UDC 613.24: 613.99

DOI: $10.21668 /$ health.risk/2020.2.04.eng

\title{
ASSESSING RISK FACTORS THAT CAN CAUSE OVERWEIGHT AND OBESITY IN WOMEN OF REPRODUCTIVE AGE
}

\author{
E.L. Makarova ${ }^{1}$, A.A. Olina ${ }^{2}$, M.M. Padrul ${ }^{3}$ \\ ${ }^{1}$ M.A. Tver'ye's Municipal Clinical Hospital, 2 Brat'ev Ignatovykh Str., Perm, 614600, Russian Federation \\ ${ }^{2}$ D.O. Ott's Scientific and Research Institute for Obstetrics, Gynecology, and Reproductology, \\ 3 Mendeleevskaya line, Saint Petersburg, 199034, Russian Federation \\ ${ }^{3}$ Perm State Medical University named after E.A. Wagner, 26 Petropavlovskaya Str., Perm, 614000, Russian Federation
}

\begin{abstract}
We examined 226 women of reproductive age who permanently resided in Perm. Our research goal was to examine certain risk factors and assess their effects on overweight and obesity in women of reproductive age.

All the patients were divided into 2 groups; the reference one was made up of 123 women with normal body weight; the test one included 103 women with overweight and obesity. We determined body mass index (BMI) of each woman; obesity type (in case BMI was higher than $25 \mathrm{~kg} / \mathrm{m}^{2}$, namely android or gynoid one; physical activity; nutrition stereotypes; smoking status (more than 5 cigarettes a day daily for not less than 1 months); sleeping disorders; research season; concomitant gastrointestinal diseases and liver diseases. We calculated relative risk of obesity and BMI predictors.

The research revealed a significant correlation between overweight and obesity and elevated risks of unhealthy nutrition stereotypes $(R R=3.3)$; low physical activity $(R R=2.6)$; age exceeding $35(R R=2.1)$; smoking $(R R=1.8)$; gastrointestinal diseases and liver diseases ( $R R=1.5)$; sleeping disorders $(R R=1.5)$. Women from the test group had improper eating habits and nutrition behavior as opposed to their counterparts from the reference group. Each second patient who suffered from android obesity was also a smoker. Winter season didn't turn out to be a predictor of fat metabolism disorders.

Therefore, having analyzed pre-obesity and obesity risk, we recommend efficient activities performed in public healthcare and personal adherence to healthy lifestyle as it will allow reducing body weight of fertile Russian women. Doctors of any specialty should share the responsibility for preserving health of future parents and generations.
\end{abstract}

Key words: risk factors, obesity, overweight, physical activity, season, nutrition stereotype, smoking, sleeping disorders.

«Overweight epidemic» is now spreading fast both in developed and developing countries. More than 500 million people worldwide have overweight as their body mass index (BMI) varies from 25 to $29.9 \mathrm{~kg} / \mathrm{m}^{2} .250 \mathrm{mil}-$ lion people suffer from obesity (their BMI exceeds $30 \mathrm{~kg} / \mathrm{m}^{2}$ ) $[1,2]$. The mankind can't cope with obesity; everybody seems to know how to lose weight but nobody actually manages to do it. Since 90ties last century people in Russia «have put on considerable weight». Obesity, both in the country and in Perm region, has grown by 4.8 times over the last 15 years [3]. According to official statistic data (2017), in Russia 29\% women aged 18-45 have obesity; in Perm region $-13 \%$. According to the Statistic Report Form No. 12 (official statistical data collected in Perm region), in 2018 «obesity»
(E.66 as per ICD-10) was diagnosed in $9 \%$ of cases when people older than 18 applied for medical health. And still, results of periodical medical examinations performed among working population and students in Perm revealed even higher figures. Obesity was diagnosed in $15 \%$; «morbid obesity» was detected in $5 \%$ cases (BMI exceeded $40 \mathrm{~kg} / \mathrm{m}^{2}$ ); overweight (pre-obesity) was diagnosed in each $6^{\text {th }}$ examined person [3]. We should note that official statistical data can't be a basic data source for determining actual prevalence of diseases associated with lipid metabolism disorders as people rarely apply for medical health due to having overweight. So, it is truly vital to examine actual prevalence of such diseases in various age groups as well as their contemporary etiological and pathogenetic aspects.

(C) Makarova E.L., Olina A.A., Padrul'M.M., 2020

Elena L. Makarova - Candidate of Medical Sciences, obstetrician-gynecologist at the Municipal Perinatal Center (e-mail: makarova_803@mail.ru; tel.:+7 (904) 849-37-70; ORCID: https://orcid.org/0000-0002-1330-8341).

Anna A. Olina - Doctor of Medical Sciences, Professor, First Deputy Director (e-mail: olina29@mail.ru; tel.: +7 (922) 329-53-62; ORCID: http://orcid.org/0000-0001-9101-7569).

Mikhail M. Padrul' - Doctor of Medical Sciences, Professor, Head of the Obstetrics and Gynecology Department (e-mail: rector@psma.ru; tel.: +7 (342) 217-20-21; ORCID: http://orcid.org/0000-0002-6111-5093). 
Fat accumulation is hazardous for people of any sex and age. However, bearing in mind the latest demographic trends in the RF (negative natural growth, ageing, and first-time mothers becoming older) it is necessary to pay more attention to young women of reproductive age as they secure reproductive potential in the country. Future mothers with overweight trigger transformation of genes that are responsible for metabolic processes in lipocytes thus creating a so called «protected fat tissues» in their children [4]. A number of fat cells multiplies during fetal development [5]. This genetically determined obesity will become hardly curable in future.

«Obesity» as a diagnosis is not registered by doctors who treat related pathologies. For example, a young woman doesn't come to a gynecologist-obstetrician because she has overweight; instead she comes to treat menorrhalgia or infertility, that is, reproductive disorders related to fat metabolism disorders. Even if she manages to get pregnant, an imbalance in fat tissue hormones can cause certain complications, both for a mother (miscarriage, gestational pancreatic diabetes, preeclampsia, fetoplacental failure, etc.) and for a fetus (hypersomia, birth traumas, carbohydrates metabolism disorders etc.) [6-12]. At present, a wide range of research works are concentrating on prenatal programming of obesity. As a result, experts have managed to reveal an adaptation reaction in a fetus as a response to nutrition factors and its ability to provide survival via epigenetic modification of genes that participate in multiple key regulatory cycles [4]. Clinically significant adaptation to changes in nutrition that takes place during fetal development is able to become apparent as a primary component in a metabolic syndrome. Consequently, obesity in an adult person is not only a result of an unhealthy lifestyle but also a disease predetermined at early stages of development and not genetic in its essence.

Evolution biology implies that a living individual should strive for food in order to survive as it allows renewing energy resources that are stored in a body as fat tissues. Traditionally, starvation was much more hazardous for life than overeating. However, overall economic progress has resulted in food becoming much more available for people; huge variety of tasty and high-calorie food doesn't require great physical efforts to obtain it and issues related to starvation are now replaced with excess consumption. Food industry is ready to provide high-calorie products that are easy to assimilate, have minimal nutrition value and a lot of calories, and contain taste enhancers. It makes a person to consume them more and more without any feeling of satiation.

Obesity can develop due to multiple factors that can produce their effects both together and separately. The most widely spread factors are genetic predisposition, lifestyle (overeating and hypodynamia), and endocrine systems dysfunctions [13]. Since researchers on genome became possible, a lot of genes have been identified that code functions of various sections in body mass regulation and metabolism. However, identified locuses predetermine less than $5 \%$ of discrepancies in BMI [4]. Disputable issues related to impacts exerted on excess fat occurrence in a body by intoxications, sleep deprivation, water metabolism disorders, and microbiota require further investigation.

«Obesity» epidemic will only develop more rapidly due to scientific and technical progress; therefore, it will still be vital to examine behavioral peculiarities (lifestyle) of patients with overweight and obesity.

Our research goal was to examine certain risk factors and estimate their effects on overweight and obesity occurrence among women of reproductive age.

Data and methods. The research was accomplished in a clinic belonging to E.A. Vagner's Perm State Medical University, and a perinatal center of M.A. Tver'ye Municipal Hospital. Overall, we examined 226 women of reproductive age permanently residing in Perm. The patients were divided into 2 groups according to their BMI; group A $(n=123)$ was made up of women with normal body weight (reference group); group B $(n=103)$ included women with fat metabolism disorders (test group).

We determined the following parameters for each woman:

1. BMI as the body weight in kilos $(\mathrm{kg})$ divided by the square of the body height in meters $\left(\mathrm{m}^{2}\right)$. BMI equal to $25-29.9 \mathrm{~kg} / \mathrm{m}^{2}$ meant a woman had overweight; BMI being $30 \mathrm{~kg} / \mathrm{m}^{2}$ 


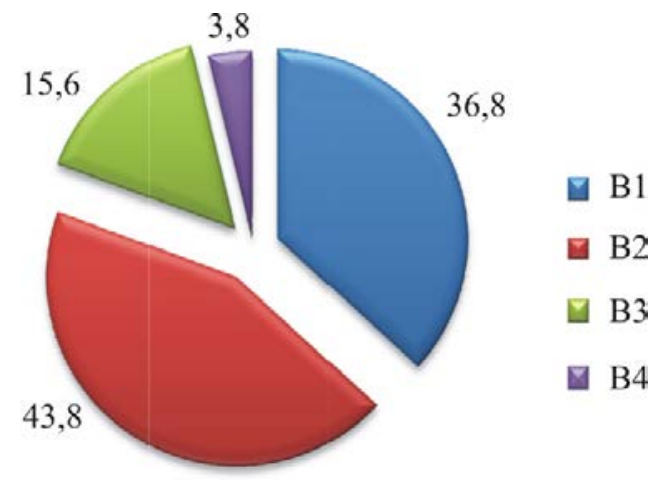

Figure 1. Test group structure depending on BMI (in \%)

and higher meant she had obesity. The test group was divided into subgroups (Figure 1): women in subgroup B1 had BMI varying from 25.0 to 29.9 (overweight); subgroup B2, $\mathrm{BMI}=30.0-34.9$ (class 1 obesity); subgroup $\mathrm{B} 3, \mathrm{BMI}=35.0-39.9$ (class 2 obesity); subgroup B4, BMI exceeding $40.0 \mathrm{~kg} / \mathrm{m}^{2}$ (class 3 obesity).

2. Obesity type, android or gynoid. To determine it, we calculated $(\mathrm{K})$ coefficient as waist circumference (WC) divided by thigh circumference (TC). In case $K=0.8$ and lower, obesity was considered gynoid (GO); in case $\mathrm{K}=0.81$ and higher, obesity was android (AO) (Table 1).

3. Physical activity (PA). In the given work, we applied a population technique for assessing PA (a questionnaire recommended by the WHO); the examined cohort was divided into two categories basing on the results. The $1^{\text {st }}$ category were sufficiently active women, their energy costs reaching recommended levels and being not less than $500 \mathrm{MET} / \mathrm{min}$ per week. The $2^{\text {nd }}$ category included women who were not physically active (less than $500 \mathrm{MET} / \mathrm{min}$ per week) [14]. GPAQ (Global Physical Activity Questionnaire) contains questions aimed at determining amounts of time spent on three types of PA: at work, during travelling from place to place, and at leisure. «Sufficient» PA was taken as per levels recommended by the WHO for adults, $150 \mathrm{~min}$ moderately intense PA or 75 min intense PA per week, or an equivalent combination of moderately intense and intense PA. Additionally, we calculated individual energy costs borne by a respondent. When calculating overall energy costs in MET with the use of GRAP data, we took 1 minute of moderate $\mathrm{PA}$ as being equal to $4 \mathrm{MET}$; 1 minute of intense PA, 8 MET. Accordingly, energy costs being $600 \mathrm{MET}$ per week or more were considered sufficient [15]. GPAQ has been validated multiple times, tested in terms of reproducibility, and recommended as a tool for estimating PA with the STEPS international system for monitoring over risk factors causing noncommunicable diseases.

4. Adherence to nutrition stereotypes. The factor was assessed via 24-hour observation over a daily ration together with analyzing its structure as per specific food products; to do that, all the female participants were offered to fill in relevant questionnaires. A list of products recommended by the Institute for Obstetrics and Gynecology of the RAS was taken as a criterion for assessing an average daily ration consumed by women. Adherence was considered satisfactory if a ration and the list were similar; otherwise, it was considered unsatisfactory ${ }^{1}[16]$.

Table 1

Characteristics of the examined groups

\begin{tabular}{|l|c|c|c|c|c|}
\hline \multicolumn{1}{|c|}{ Group } & Age, years & Weight, kg & BMI, kg/m & $\begin{array}{c}\text { GO (from as group } \\
\text { as per a row) }\end{array}$ & $\begin{array}{c}\text { AO (from as group } \\
\text { as per a row) }\end{array}$ \\
\hline Group A $(n=123)$ & $23.6 \pm 0.15$ & $63.8 \pm 1.29$ & $21.5 \pm 0.37$ & - & - \\
\hline Group B $(n=103)$ & $24.6 \pm 0.37$ & $78.8 \pm 2.59$ & $28.9 \pm 0.43$ & $62.1 \%$ & $37.9 \%$ \\
\hline Subgroup B1 $(n=38)$ & $23.6 \pm 0.51$ & $72.4 \pm 1.83$ & $26.6 \pm 0.31$ & $76.3 \%$ & $23.7 \%$ \\
\hline Subgroup B2 $(n=45)$ & $24.1 \pm 0.49$ & $88.4 \pm 1.10$ & $32.5 \pm 0.38$ & $62.2 \%$ & $37.8 \%$ \\
\hline Subgroup B3 $(n=16)$ & $24.7 \pm 0.31$ & $98.3 \pm 2.11$ & $36.8 \pm 0.55$ & $37.5 \%$ & $62.5 \%$ \\
\hline Subgroup B4 $(n=4)$ & $24.0 \pm 0.61$ & $107.6 \pm 1.6$ & $41.5 \pm 0.57$ & $25.0 \%$ & $75.0 \%$ \\
\hline
\end{tabular}

${ }^{1}$ MG 2.3.1.2432-08. Rational nutrition. Standards for physiological needs in energy and nutrients for different population groups in the Russian Federation: methodical guidelines. Moscow, Rospotrebnadzor's Center for Hygiene and Epidemiology, 2009, 36 p. (in Russian). 
5. Smoking (more than 5 cigarettes a day daily for not less than 1 month).

6. An examination taking place during a specific season. Women were selected for examination during a cold season (from October 01 to April 30) and a warm one (from May 01 to September 30$)$ in a city located at $59^{\circ}$ northern latitude (Perm).

7. Sleep disorders were revealed with a questionnaire that allowed estimating sleep quality as per a 5-score scale according to 5 criteria basing on subjective descriptions given by patients (Table 2). To interpret the results, we calculated a total score. A total score equal to 22 or higher meant a patient didn't have any sleep disorders; 19-21 scores meant borderline sleep disorders; less than 19 scores, apparent sleep disorders [17].

8 . We determined whether patients suffered from concomitant diseases of the gastrointestinal tract and liver such as gastroesophageal disease, non-alcoholic hepatosis, and cholelithiasis; to do that, clinical and instrumental data were applied (complains, a medical examination, and US of the abdominal cavity organs).

All the obtained data were statistically analyzed in «Biostatistics» Center (Tomsk). Selected parameters that are given in the text and tables below have the following denomi- nations: $\mathrm{n}$ means a number of people in an analyzed sub-group; Me, median; $25 \%$ and $75 \%$, interquartile range; $M$, simple mean; $\mathrm{S}$, standard deviation; $\mathrm{m}$, error of the mean; $\mathrm{p}$, achieved significance. Critical significance was taken to be equal to $5 \%$. We applied the following statistical analysis procedures: testing whether quantitative attributes distribution was normal with Kolmogorov-Smirnov test; contingency tables analysis; risk ratio with calculating Pearson's $\chi^{2}$-square; two-tailed Fischer's test, \%. Relative risk $(R R)$ was calculated with the use of fourfold contingency tables. At $R R>1$ it was concluded that a factor caused an increase in a number of outcomes (a direct correlation).

Results and discussion. Correlation analysis of impacts exerted by age on weight didn't reveal any direct dependence in all groups. But still, picking out specific age category «younger than $35 »$ and «35 and older» within the groups allowed revealing certain contingency between weight and age as well as BMI and age within «35 and older» subgroup (Table 3). Literature data indicate that metabolic reactions physiologically tend to slow down as a person grows older; certain hormonal shifts also occur in older people and they can result in fat accumulating in a female body $[18,19]$.

Table 2

A questionnaire for obtaining a score estimate of subjective sleep descriptions (Vein A.M., 2016)

\begin{tabular}{|l|c|c|c|c|c|}
\hline \multirow{2}{*}{ Sleep description } & \multicolumn{5}{c|}{ Scores } \\
\cline { 2 - 6 } & 5 & 4 & 3 & 2 & 1 \\
\hline Time necessary to fall asleep & Instantly & Not long & Average & Long & Very long \\
\hline Sleep duration & Very long & Long & Average & Short & Very short \\
\hline Awakenings at night & Never & Rarely & Sometimes & Often & Very often \\
\hline Dreams & Never & Sometimes & Average & Multiple & Multiple and troubled \\
\hline Sleep quality & Excellent & Good & Average & Poor & Very poor \\
\hline Awakening quality & Excellent & Good & Average & Poor & Very poor \\
\hline
\end{tabular}

Contingency with BMI higher than $25 \mathrm{~kg} / \mathrm{m}^{2}$

Table 3

\begin{tabular}{|l|c|c|}
\hline \multicolumn{1}{|c|}{ Parameter } & Acheived «p» & Cramer's V \\
\hline Age being 35 and older & 0.0412 & 0.3030 \\
\hline Obesity type: android/gynoid & 0.0001 & 0.6694 \\
\hline Unsatisfactory nutrition & 0.0231 & 0.3437 \\
\hline Season (cold: October 01 - April 30) & 0.1880 & 0.2775 \\
\hline Low PA & 0.008 & 0.3969 \\
\hline Chronic diseases of the gastrointestinal tract and liver & 0.8620 & 0.1305 \\
\hline Sleep disorders & 0.2361 & 0.2899 \\
\hline
\end{tabular}




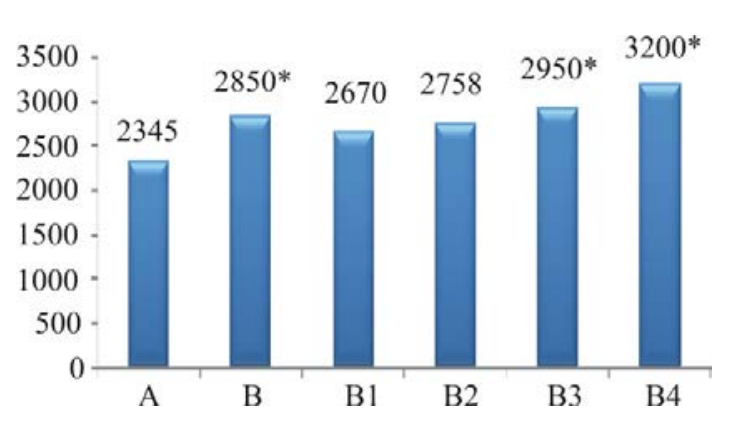

Figure 2. Daily calorie consumption (Kcal) by women from different subgroups

* means $p<0.005$ (against the group A)

We analyzed questionnaires on adherence to specific nutrition stereotypes and revealed significant nutritional disorders in the group B. We detected that women in the basic group B and in all subgroups daily consumed calories in a quantity than was more than 2,600 kilocalories (Figure 2). And it is especially alerting as a woman in reproductive age employed at a workplace with mental labor and low physical loads is recommended to consume 2,400-2,600 kcal per day [15]. We revealed a direct dependence between weight and consumed calories quantity.

We detected that $85 \%$ patients from the basic group consumed fats in excess quantities; there were only $34 \%(p<0.01)$ women in the control group who consumed them in such quantities. Women from both groups mostly consumed animal fats (butter, milk fats, and animal fats with meat). As opposed to vegetable fats, these fats have higher concentrations of saturated fatty acids such as palmitic acid, stearic acid, etc. A need in saturated fatty acids accounts for only $5 \%$ of the total daily ration or $30 \%$ of the total quantity of fats consumed a day. Total quantity of all consumed fats should not exceed $1 \mathrm{gr} / \mathrm{kg}$ of body weight. Only $30 \%$ of saturated fats break down in a body; the rest doesn't participate in metabolism and produces negative effects on functioning of all organs and systems in a body (atherogenicity index grows, fats accumulate in deposits).

Respondents from both groups consumed vegetable oil and fish oil in quantities not more than 10 grams a day thus depriving their bodies of Omega-3,6,9 fat acids and fat-soluble vitamins; they didn't consume those health- giving nutrients in sufficient quantities. And it should be noted that these substances produce hypocholesteremic, hypotriglyceridemic, antithrombotic, anti-inflammatory, cardioprotective, and oncoprotective effects [20].

Excess energy intake in the test group was due to consumed food being high-caloric with fats prevalence in a daily ration and daily nutrition rhythms being impaired.

Practically all women with fat metabolism imbalance had disrupted daily nutrition rhythms (91\%); the same was detected for each fifth woman with normal body weight (23\%, $p<0.001$ ). Abundant meals at night (after 10 p.m.) were the most frequent (33\% and $7 \%$ accordingly, $p<0.01)$. Fast-food meals were detected in $42 \%$ cases in the test group and $15 \%$ cases in the control one $(p=0.02)$; sweet fizzy waters consumption was detected in $52 \%$ and $23 \%$ cases accordingly $(p=0.02)$. It is rather alerting that practically all patients from the test group (91\%) and $2 / 3$ patients in the control one $(62 \%)$ consumed mostly preserved and refined food products. It is well-known that manufacturers add taste enhancer and stabilizers in semi-cooked and preserved food products. Such substances induce overeating and block any feeling of being sated with food. Semi-finished products are often fried in a great quantity of oil and it is an additional source of «excess» calories in a daily ration.

Besides, we detected nutritional behavior disorders in the test group. Hyperphagic reaction was revealed in $68 \%$ cases in the test group and in $39 \%$ cases in the control one as per questioning results. Such a state occurs under psychoemotional strain, anxiety, or stress. Appetite grows drastically, and a person has an overwhelming wish to eat; food is not differentiated, and a person eats anything he or she can get still giving preference to fat and sweet products. Another nutrition behavior disorder, compulsive hyperphagia, was detected in each third patient in the test group (33\%) and in less than $5 \%$ patients in the control group. This eating disorder is characterized with sudden uncontrollable food consumption that has nothing to do with physiological satiation. Compulsive overeating is believed to occur due to depres- 
sion, melancholy, and low self-esteem that are often caused by disharmony in family relations [21]. Night hyperphagia was detected in $24 \%$ women from the test group.

Nutrition behavior disorders get only worse due to social significance attributed to meals. A lot of families go to fast-food cafes («McDonald's», «KFC», «Chicken», etc.) to celebrate a family event or to give a «reward» to children or adults in a family; such cafes provide their clients with food that contains a lot of carbohydrates and fats.

Therefore, unsatisfactory nutrition as a significant factor was detected in $75 \%$ cases in the test group and in $46 \%$ cases in the control one. This predictor turned out to be statistically significant $\left(\chi^{2}=31.8, p<0.001\right)$ and one of three most significant factors in calculation of relative risks $(R R=3.33$ at $C I 1.95-5.16)$ that could cause fat metabolism disorders (Table 4).

Individual energy consumption by a person depends on three factors. The first one is basic metabolism that corresponds to energy expenses spent on maintaining basic physiological functions under normal conditions. The second is dynamic effects produced by food (thermogenic effects) that account for approximately $5-10 \%$ of the overall energy expenses and are associated with additional energy spent on digestion. The third one is physical activity that requires the most energy [15]. Over the last decades normal physical activity of women in Russia during their leisure time is replaced with hypodynamia, for example watching TV or spending time in the Internet instead of doing sports [22].

We examined such a predictor as «physical activity» in our research and obtained the following results. Each second woman $(52.1 \%)$ with normal body weight was sufficiently physically active; the same was true only for each fifth woman with fat metabolism disorders $\left(22.6 \% ; \chi^{2}=20.858, p<0.001\right)$. When giving comments in questionnaires, women explained their low physical activity by changes in external living conditions (sedentary activities both at home and at work) and changes in ways to travel from place to place (elevators and cars). Such factors as growing urbanization, physical labor being replaced with machines, and computerization of many spheres lead to low physical activity of people. Besides, internal factors were also significant, namely, no motivation to be physically active and mobile (on-line shopping and food delivery) and do sports; existing habits in a family, unwillingness to pursue healthy lifestyle. $3.5 \%$ women from the test group noted they loved themselves with any body weight as they belonged to so called «body positive» movement advertised by mass media and social networks. Unfortunately, this movement only aggravates a problem related to such a disease as «obesity». Low PA or even absence of it and excess food consumption are not disapproved of by such patients and they consider it an insult when somebody mentions diets or fitness centers in talks with them.

Table 4

Calculating relative risks развития of fat metabolism disorders in women of reproductive age

\begin{tabular}{|l|c|c|c|c|c|}
\hline \multicolumn{1}{|c|}{ Risk factor } & $R R$ & $\begin{array}{c}\text { Low limit } \\
\text { of 95\% } C I\end{array}$ & $\begin{array}{c}\text { Upper limit } \\
\text { of 95\% CI }\end{array}$ & $p$ & $\begin{array}{c}\text { Correlation } \\
\text { strength }\end{array}$ \\
\hline Nutrition & 3.333 & 1.959 & 5.669 & $<0.001$ & Average* \\
\hline Physical activity & 2.617 & 1.583 & 4.327 & $<0.001$ & Average* \\
\hline Age 35+ & 2.036 & 1.594 & 2.601 & $<0.001$ & Average* \\
\hline Smoking & 1.790 & 1.376 & 2.330 & $<0.001$ & Average* \\
\hline Cold season & 1.174 & 0.870 & 1.585 & 0.286 & Insignificant*** \\
\hline $\begin{array}{l}\text { Gastrointestinal tract } \\
\text { and liver diseases }\end{array}$ & 1.499 & 0.937 & 1.536 & 0.002 & Average* \\
\hline Sleep disorders & 1.456 & 1.060 & 2.001 & 0.016 & Weak** $^{* * 1}$ \\
\hline
\end{tabular}

$\mathrm{N}$ o t e : * means average correlation at $R R>1.450 ; * *$ means weak correlation at $R R=1.449-1.2$; *** means insignificant correlation at $R R<1.2$. 
Recommended physical loads often result in patients being disappointed as they don't allow achieving fast and significant weight loss; it is due to redistribution of fat mass that goes down whereas muscle mass grows. And in spite of a low decline in overall body weight there is a decrease in visceral fat; it results in insulin becoming more sensitive to tissue receptors. Single short-term physical loads (less than 45 minutes) provide only liver glycogen expense while long-term ones (more than 45 minutes) lead to fat deposits losses [22].

Genetically people are prone to fat accumulating before a cold season starts [23]. It was very important for our predecessors. Fat tissue had several functions; it protected from cold and provided necessary energy in late winter and early spring when food reserves were scarce. Another probable reason for this seasonal increase in weight is influence exerted on a human body by hormones. Changes in their levels result in changing appetite, in this case, in its growing, and we subconsciously start to eat more fatty food. Besides, shorter daylight hours in winter can lead to a seasonal depression, and an efficient way to elevate one's mood is to increase consumption of products that contain carbohydrates in high quantities (chocolate, sweets, buns, cakes, etc.). Most people tend to have significantly low PA in winter. Another reason is a decrease in vitamin D quantity that results in slower fat break-up and induces its accumulation [20]. According to our data, there were no revealed correlations between a seasonal factor (winter-summer) as overweight predictor and obesity (Table 4).

Low melatonin concentration caused by sleep disorders produces negative effects on metabolism. As per data given by E. Van Cauter, repeated nights with not enough sleep reduce sensitivity to insulin without its compensatory secretion [24]. In our research we detected a weak correlation between sleep disorders as a risk factor and obesity $(R R 1.456$ at $C I 1.060-2.001 p=0.016$ ). It can probably be due to examined women being young as the factor becomes truly significant during menopause [19].

There was an average correlation between smoke and fat metabolism disorders; smoking women ran 1.8 times higher risk of obesity than non-smoking ones. Android obesity occurrence turned out to be statistically significant for smoking women against non-smoking ones with excess fat tissues in their bodies $(p<0.05)$ (Figure 3). There is a positive correlation between a number of smoked cigarettes and abdominal fat accumulation [25]. Nicotine makes for developing resistance to insulin and type-II diabetes occurrence; it also contributes into lipid profile shifting towards atherogenicity. Even if smoking people probably weighed less than in case they didn't smoke, they still had high contents of visceral and subcutaneous fat tissues thus running elevated risks of cardiovascular diseases [26].

Effects produced by nicotine make people strongly addicted to it and it is a basic reason for smokers constantly craving for cigarettes. Giving up smoking often results in growing body weight and it is the main obstacle that prevents smokers, especially female ones, from abandoning this bad habit or makes them return to it shortly after giving it up [25]. Therefore, an issue related to determining what is a cause and what is an effect in "smoking - obesity» correlation requires further investigation.

Chronic gastric and liver diseases (gastroesophageal disease, non-alcoholic hepatosis, and cholelithiasis in a compensation period) as a risk factor had average correlation with obesity with relative risk being equal to 1.499 . When body weight grows, certain changes occur in it and they can become a pathogenetic basis for occurrence of many diseases in the digestive organs [27]. Pathophysiological processes occurring in

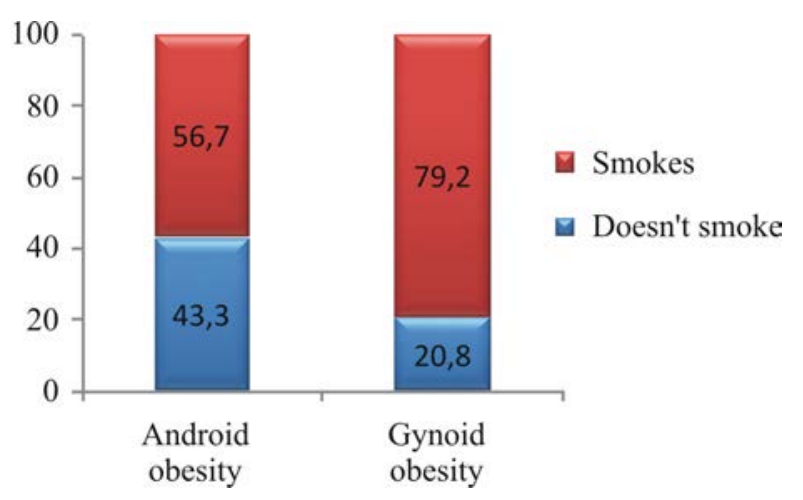

Figure 3. Number of smoking women (\%) in the test group

Depending on obesity type 
a person with obesity, such as elevated abdominal pressure, excess synthesis of adipokins and cholesterol, elevated secretion of free fatty acids, result from excess fat tissue accumulation and redistribution in a body. Therefore, these diseases can be considered an outcome caused by obesity and not a cause of it. A certain vicious circle occurs when obesity causes diseases and they, in their turn, induce further weight increase.

Conclusions. Therefore, our research allowed revealing a significant correlation between elevated risk of overweight and obesity and unsatisfactory nutrition stereotypes $(R R=3.3)$; low physical activity $(R R=2.6)$; age being 35 and older $(R R=2.1)$; smoking $(R R=1.8)$, gastric and liver diseases $(R R=1.5)$; sleep disorders $(R R=1.5)$. It is necessary to implement efficient activities in public healthcare aimed at motivating fertile Russian women to pursue healthy lifestyle and keep fit.
Patients with overweight and obesity should be treated as running high risks associated with fat metabolism disorders not only in themselves but in their future children as well. Monitoring over weight should become a standard procedure during preparation to pregnancy and birth. It is primary healthcare clinics that can successfully implement programs aimed at control over weight. Doctors of all specialties should bear responsibility for preserving health of future parents and new generations. To changes one's lifestyle is simultaneously a very simple and very complicated task that can be solved only by combining efforts made by both patients and their doctors.

Funding. The research was not granted any sponsor support.

Conflict of interests. The authors declare there is no any conflict of interests.

\section{References}

1. Afshin A., Forouzanfar M.H., Reitsma M.B., Sur P., Estep K., Lee A., Marczak L., Mokdad A.H. [et al.]. Health Effects of Overweight and Obesity in 195 Countries over 25 Years. Engl. J. Med., 2017, vol. 377, pp. 13-27. DOI: 10.1056/NEJMoa1614362

2. Abarca-Gómez L., Abdeen Z.A., Hamid Z.A., Abu-Rmeileh N.M., Acosta-Cazares B., Acuin C., Adams R.J., Aekplakorn W. [et al.]. Worldwide trends in body-mass index, underweight, overweight, and obesity from 1975 to 2016: a pooled analysis of 2416 population-based measurement studies in 128.9 million children, adolescents, and adults. The Lancet, 2017, vol. 10113, no. 390, pp. 2627-2642. DOI: $10.1016 / \mathrm{s} 0140-6736(17) 32129-3$

3. Demicheva T.P., Shilova S.P. Statistical analysis of endocrine disorders prevalence in perm territory (according to various sources of information). Sotsial'nye aspekty zdorov'ya naseleniya: Elektronnyi zhurnal, 2015. Available at: https://cyberleninka.ru/article/n/statisticheskiy-analiz-rasprostranyonnosti-bolezney-endokrinnoy-sistemy-v-permskom-krae-po-razlichnym-istochnikam-informatsii (13.11.2020) (in Russian).

4. Pigeyre M., Yazdi F.T., Kaur Y., Meyre D. Recent progress in genetics, epigenetics and metagenomics unveils the pathophysiology of human obesity. Clin. Sci, 2016, vol. 130, no. 12, pp. 943-986. DOI: $10.1042 / \operatorname{cs} 20160136$

5. Jungheim E.S., Travieso J.L., Carson K.R., Moley K.H. Obesity and Reproductive Function. Obstetrics and Gynecology Clinics of North America, 2012, vol. 39, no. 4, pp. 479-493. DOI: 10.1016/j.ogc.2012.09.002

6. Jasmine F., Stanley J.L., Baker P.N., Reynolds C.M., Vickers M.H. The Pathophysiology of Gestational Diabetes Mellitus. Int. J. Mol. Sci, 2018, vol. 19, no. 11, pp. 3342. DOI: 10.3390/ijms19113342

7. Obesity in Pregnancy/ACOG Practice Bulletin N156. Obstet Gynecol, 2015, vol. 126, no. 6, pp. 112-126. DOI: 10.1097/AOG.0000000000001211

8. Lisonkova S., Muraca G.M., Potts J., Liauw J., Chan W.S., Skoll A., Lim K.I. Association Between Prepregnancy Body Mass Index and Severe Maternal Morbidity. JAMA, 2017, vol. 14, no. 318 (18), pp. 1777-1786. DOI: 10.1001/jama.2017.16191

9. Catalano P.M., Shankar K. Obesity and pregnancy: mechanisms of short term and long term adverse consequences for mother and child. $B M J$, 2017, vol. 8, no. 356, pp. 1. DOI: 10.1136/bmj.j1

10. Cavalcante M.B., Sarno M., Peixoto A.B., Araujo Júnior E., Barini R. Obesity and recurrent miscarriage: A systematic review and meta-analysis. J. Obstet. Gynaecol. Res., 2019, vol. 45, no. 1, pp. 30-38. DOI: 10.1111/jog.13799

11. Turner D., Carmen M.D. Maternal obesity and cesarean section delivery: additional risk factors for neonatal hypoglycemia? Journal of Perinatology, 2019, vol. 39, no. 8, pp. 1057-1064. DOI: 10.1038/s41372-019-0404-z 
12. Gorbatenko N.V., Bezhenar' V.F., Fishman M.B. Obesity and reproductive health of women. Ozhirenie i metabolizm, 2017, vol. 14, no. 1, pp. 3-8 (in Russian).

13. Dedov I.I., Mel'nichenko G.A., Shestakova M.V., Troshina E.A., Mazurina N.V., Shestakova E.A., Yashkov Yu.I., Neimark A.E. [et al.]. Russian national clinical recommendations for morbid obesity treatment in adults. 3rd revision (Morbid obesity treatment in adults). Ozhirenie i metabolism, 2018, vol. 15, no. 1, pp. 53-70 (in Russian).

14. Thirteenth general programme of work, 2019-2023. Geneva, World Health Organization Publ., 2018. Available at: https://www.who.int/ru/news-room/fact-sheets/detail/healthy-diet (15.11.2019).

15. WHO STEPwise approach to NCD risk factor surveillance. Geneva, World Health Organization Publ., 2018. Available at: www.who.int/chp/steps (15.11.2019).

16. Nikityuk D.B. Sposob otsenki individual'nogo potrebleniya pishchi metodom 24-chasovogo sutochnogo vosproizvedeniya pitaniya [A procedure for assessing individual food consumption via 24-hour reproduction of meals]. Moscow, FGBUN «FITs pitaniya i biotekhnologii» Publ., 2016, 38 p. (in Russian).

17. Somnologiya i meditsina sna. Natsional'noe rukovodstvo pamyati A.M. Veina i Ya.I. Levina [Somnology and sleep medicine. The national guide issued in memory of A.M. Vein and Ya.I. Levin]. In: M.G. Poluektov ed. Moscow, Medforum Publ., 2016, pp. 11-55 (in Russian).

18. Achkasov E.E., Rapoport S.I., Runenko S.D., Razina A.O. Obesity: the modern view of a problem. Klinicheskaya meditsina, 2016, vol. 94, no. 5, pp. 333-338. DOI: 10.18821/0023-2149-2016-94-5333-338 (in Russian)

19. Serov V.N., Prilepskaya V.N., Ovsyannikova T.V. Ginekologicheskaya endokrinologiya [Gynecological endocrinology]. Moscow, «MEDpress-inform» Publ., 2017, 323 p. (in Russian).

20. Gromova O.A., Torshin I.Yu. Vitamin D: smena paradigm [Vitamin D: a change of paradigm]. Moscow, GEOTAR-Media Publ., 2017, 568 p. (in Russian).

21. Berthoud H.R., Lenard N.R., Shin A.C. Food reward, hyperphagia, and obesity. Am. J. Physiol. Regul. Integr. Comp. Physiol., 2011, no. 6, pp .1266-1277.

22. Leskova I.V., Ershova E.V., Nikitina E.A., Krasnikovskii V.Ya., Ershova Yu.A., Adamskaya L.V. Obesity in Russia: modern view in the light of a social problems. Ozhirenie i metabolizm, 2019, vol. 16, no. 1, pp. 20-26 (in Russian).

23. Philip A., Finlin B.S., Zhu B., Rasouli N. The Effects of Temperature and Seasons on Subcutaneous White Adipose Tissue in Humans: Evidence for Thermogenic Gene Induction. The Journal of Clinical Endocrinology \& Metabolism, 2014, vol. 99, no. 12, pp. E2772-E2779. DOI: 10.1210/jc.2014-2440

24. Reutrakul S., Van Cauter E. Sleep influences on obesity, insulin resistance, and risk of type 2 diabetes. Metabolism, 2018, vol. 7, vol. 84, pp. 56-66. DOI: 10.1016/j.metabol.2018.02.010

25. Clair C., Chiolero A., Faeh D., Cornuz J., Marques-Vidal P., Paccaud F., Mooser V., Waeber G., Vollenweider P. Dose-dependent positive association between cigarette smoking, abdominal obesity and body fat: cross-sectional data from a population-based survey. BMC Public Health, 2011, no. 11, pp. 23. DOI: $10.1186 / 1471-2458-11-23$

26. Siahpush M., Singh G.K., Tibbits M., Pinard C.A., Shaikh R.A., Yaroch A. It is better to be a fat exsmoker than a thin smoker: findings from the 1997-2004 National Health Interview Survey-National Death Index linkage study. Tob. Control, 2014, vol. 23, no. 5, pp. 395-402. DOI: 10.1136/tobaccocontrol-2012-050912

27. Luzina E.V., Tomina E.A., Zhilina A.A. Obesity and diseases of digestive organs. Klinicheskaya meditsina, 2013, no. 6, pp. 63-67 (in Russian).

Makarova E.L., Olina A.A., Padrul'M.M. Assessing risk factors that can cause overweight and obesity in women of reproductive age. Health Risk Analysis, 2020, no. 2, pp. 38-46. DOI: 10.21668/health.risk/2020.2.04.eng

Received: 20.11 .2019

Accepted: 02.06.2020

Published: 30.06 .2020 